\title{
Increased plasma leptin in gestational diabetes
}

\author{
A. Kautzky-Willer ${ }^{1}$, G.Pacini ${ }^{2}$, A.Tura ${ }^{2}$, C. Bieglmayer ${ }^{3}$, B.Schneider ${ }^{4}$, B. Ludvik ${ }^{1}$, R.Prager ${ }^{1}$, W. Waldhäusl ${ }^{1}$ \\ ${ }^{1}$ Department of Internal Medicine III, Division of Endocrinology and Metabolism, University of Vienna, Vienna, Austria \\ ${ }^{2}$ Institute of Systems Science and Biomedical Engineering (LADSEB-CNR), Padova, Italy \\ ${ }^{3}$ Department of Laboratory Diagnostics, University of Vienna, Vienna, Austria \\ ${ }^{4}$ Institute of Biostatistics, University of Vienna, Vienna, Austria
}

\section{Abstract}

Aims/hypothesis. Insulin resistance as well as marked changes in body weight and energy metabolism are associated with pregnancy. Its impact on plasma leptin is not known and was determined in this longitudinal study in both diabetic and normal pregnancy.

Methods. At 28 gestational weeks plasma concentrations of leptin and B-cell hormones were measured at fasting and after an oral glucose load (OGTT:75 g) in women with gestational diabetes and pregnant women with normal glucose tolerance and compared with women who were not pregnant $(\mathrm{C})$.

Results. Plasma leptin $(\mathrm{ng} / \mathrm{ml})$ was higher $(p<0.001)$ in women with gestational diabetes $(24.9 \pm 1.6)$ than in women with normal glucose tolerance $(18.2 \pm 1.5)$ and increased in both groups when compared with the non-pregnant women $(8.2 \pm 1.3 ; p<0.0005)$. No change in plasma leptin concentrations was induced by OGTT in any group. Basal insulin release was higher $(p<0.05)$ in women with gestational diabetes compared with the pregnant women with normal glucose tolerance. Marked insulin resistance was confirmed by a $20 \%$ lower $(p<0.05)$ insulin sensitivity in subgroup analysis and a decrease of almost $40 \%$ in fasting glucose/insulin ratio $(p<0.005)$ in women with gestational diabetes. Leptin correlated in women with gestational diabetes with basal plasma concentrations of glucose $(p<0.02)$, insulin $(p<0.004)$ and proinsulin $(p<0.01)$ as well as with BMI $(p<0.001)$ and overall pregnancy induced maternal weight gain $(p<0.009)$. With normalisation of blood glucose 8 weeks after delivery in women with gestational diabetes their plasma leptin decreased $(p<0.0005)$ to $17.3 \pm 1.9 \mathrm{ng} / \mathrm{ml}$ but did not completely normalize ( $p<0.05$ vs non-pregnant women).

Conclusion/interpretation. Our data show that women with gestational diabetes without any change in plasma leptin upon oral glucose loading have increased plasma leptin concentrations during and after pregnancy, a clear association of plasma leptin with the respective concentration of glucose and insulin resistance as well as with changes in body weight, and a failure to normalize spontaneously BMI to the same extent as pregnant women with normal glucose tolerance when compared with matched control subjects. [Diabetologia (2001) 44: 164-172]

Keywords Gestational diabetes, leptin, insulin resistance, insulin secretion, glucose tolerance, body weight.
Received: 11 July 2000 and in revised form: 10 October 2000

Corresponding author: A. Kautzky-Willer, MD, Associate Professor of Medicine, University of Vienna, Department of Internal Medicine III, Division of Endocrinology and Metabolism, Währinger Gürtel 18-20, 1090 Wien, Austria.

Abbreviations: GDM, gestational diabetes.
Leptin, a polypeptide hormone originating from adipocytes, contributes to body weight control and provides negative feedback between adipose tissue and the hypothalamic satiety centre. In animal models, leptin decreases food intake but increases energy expenditure and body temperature [1-3]. Furthermore, it is found to be higher in women than in men [4] and to influence the reproductive function [5]. In humans plasma leptin is highly correlated with body fat 
mass potentially reflecting leptin resistance in obesity [6].

Insulin and glucocorticoids are regarded as important determinants for leptin synthesis and secretion. Both hormones increase with plasma leptin [7-10] during pregnancy, which is associated with increased maternal lean and fat mass as well as with considerable changes in glucose metabolism. Leptin peaks at around 28 gestational weeks, plateaus thereafter, declines slightly before delivery and falls promptly post-partum. The impact of pregnancy and glucose homeostasis on plasma leptin and its physiological role during gestation is nevertheless not completely clear in humans, in particular the differences in plasma leptin concentrations between pregnant women with diabetes and pregnant women who are without diabetes. Since gestational diabetes, a common metabolic complication during pregnancy, is closely related to Type II (non insulin dependent) diabetes mellitus and obesity in later life, an analysis of plasma leptin concentrations during pregnancy is of considerable interest. The prediabetic state of gestational diabetes is characterized by a combination of marked insulin resistance and insulin secretory impairment [11-13]. These defects normalize in part after delivery even though women with gestational diabetes frequently regain normal glucose tolerance post-partum [13-15].

Offspring of women with gestational diabetes are at an increased risk of obesity, glucose intolerance and diabetes in late adolescence and young adulthood $[16,17]$. The greatest source of perinatal morbidity in gestational diabetes remains diabetic foetopathy and the development of macrosomic infants, although there is evidence that intensive treatment of hyperglycaemia in gestational diabetics can markedly reduce the risk of excessive fetal growth. Conversely, overzealous glycaemic control during pregnancy is associated with fetal growth restriction and can even increase the risk of developing diabetes, hypertension and cardiovascular disease in later life, as suggested by epidemiological studies in subjects with low birth weight $[18,19]$. In this context it has been postulated that fetal insulin-related growth reflects not only maternal glycaemia but also fetal genetic factors that regulate fetal insulin secretion and sensitivity. Thus, the association of low birth weight and later adult insulin resistance could in part be a phenotype of genetically determined fetal insulin resistance [20].

The aims of this longitudinal study were therefore to measure plasma leptin concentrations in women with gestational diabetes before and after delivery and compare these concentrations with those in pregnant women with normal glucose tolerance and healthy non-pregnant women as well as to relate plasma leptin to plasma glucose, insulin and body weight changes and to the birth weight of newborn children. Furthermore, women with pregestational Type I (in- sulin-dependent) diabetes mellitus were included in the study to outline specific features of gestational diabetes when compared with the effects of chronic hyperglycaemia in Type I diabetes. We hypothesized that we would find higher plasma leptin concentrations in women with gestational diabetes as part of the insulin-resistance syndrome than in pregnant women with autoimmune diabetes (Type I diabetes) despite similar pregestational body weight and metabolic control during pregnancy. In addition, we tested the hypothesis that maternal plasma leptin concentrations might relate to the placental and birth weight of the newborn babies.

\section{Subjects and Methods}

Pregnant women were referred from the Obstetrics department to the outpatient clinic of the Endocrinology and Metabolism division for screening for gestational diabetes at the 28th gestational week and were tested for impaired oral glucose tolerance (OGTT, $75 \mathrm{~g}$ ) following the World Health Organisation criteria. Gestational diabetes was diagnosed when the $2 \mathrm{~h}$ plasma glucose exceeded $7.8 \mathrm{mmol} / \mathrm{l}(140 \mathrm{mg} / \mathrm{dl})$. These patients $(n=55)$ received individual nutritional counselling with instructions on the appropriate restriction of energy intake $(25-30 \mathrm{kcal} / \mathrm{kg})$ and daily self-monitoring of blood glucose. If medical nutrition therapy failed to consistently maintain fasting plasma glucose at less than $5.6 \mathrm{mmol} / \mathrm{l}(100 \mathrm{mg} / \mathrm{dl})$ and the $1 \mathrm{~h}$ post-prandial plasma glucose at less than $7.8 \mathrm{mmol} / \mathrm{l}$ $(140 \mathrm{mg} / \mathrm{dl})$ conventional intensified insulin therapy was initiated $(n=26)$.

In addition, 25 healthy pregnant women with normal glucose tolerance without any risk factors and normal glucose tolerance (75 g OGTT: $2 \mathrm{~h}$ glucose $<7.8 \mathrm{mmol} / \mathrm{l}(140 \mathrm{mg} / \mathrm{dl})$ ) and 10 pregnant women with Type I diabetes matched for preconceptual BMI and age to gestational diabetes, were included in the study (Table 1). All pregnant women with gestational diabetes were negative for islet cell antibodies (GAD, ICA, IA2). The data were obtained at gestational week 28 and 8 weeks after delivery (OGTT) as well as at term (BMI, weight gain, $\mathrm{HbA}_{1 \mathrm{c}}$, birth weight). In addition metabolic variables were determined for comparison in 10 healthy normal-weight non-pregnant control women $(C)$ of similar age (Table 1$)$. In a subgroup of pregnant women (women with gestational diabetes, GDM: $n=25$; women with normal glucose tolerance, NT: $n=15)$ and in all control women (C, $n=10)$ OGTT were done with additional samples taken for estimation of basal and total insulin secretion as well as of insulin sensitivity.

Methods. Plasma concentrations of leptin, glucose, insulin, C peptide and islet amyloid polypeptide were measured in the fasting state and $30 \mathrm{~min}$ after OGTT in all subjects. For the OGTTs, carried out to obtain additional information on stimulated pancreatic secretory capacity by using mathematical model analysis, venous blood samples were drawn in the fasting state and at 10, 20,30, 60,120, 150 and180 min after oral $75 \mathrm{~g}$ glucose loading in the morning following an overnight fast.

Blood was rapidly centrifuged and plasma glucose concentration immediately assessed using an automated glucose analyzer (Beckman, Fullerton, Calif., USA). Insulin (Serono Diagnostics, Freiburg, FRG), C peptide (CIS Bio International, Cedex, France), leptin (Human Leptin RIA kit, Linco Re- 
Table 1. Characteristics of pregnant women with gestational diabetes (GDM) and those with normal glucose tolerance during pregnancy (NT) as well as of pregnant women with Type I
Diabetes (DM I). All data for gestational weeks 28, since otherwise designated

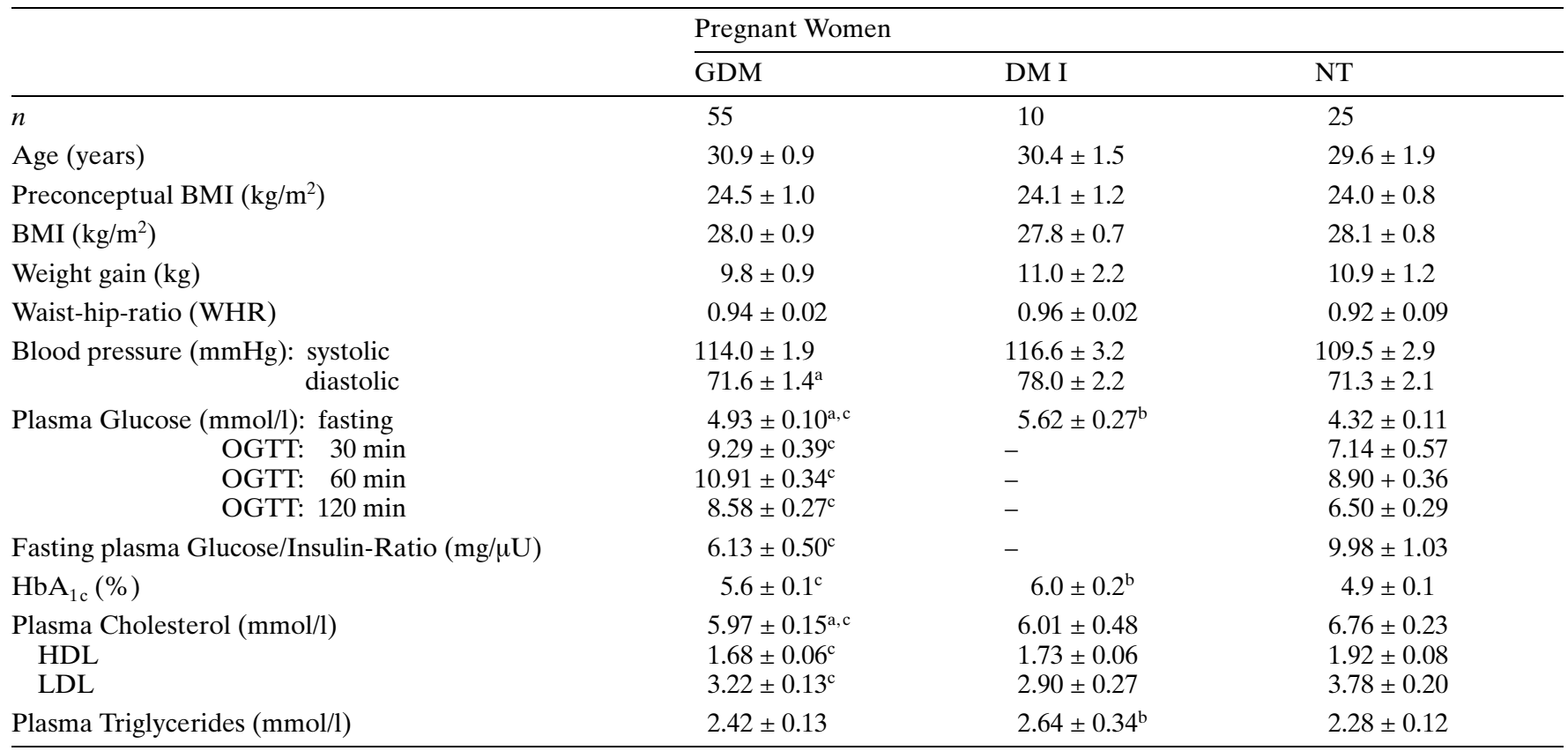

a $p<0.05$ women with gestational diabetes vs DM I

${ }^{\mathrm{b}} p<0.05$ DM I vs NT

${ }^{c} p<0.05$ GDM vs NT

search, Inc., St. Charles, Mo., USA) and proinsulin (Linco Research, Inc., St. Charles, Mo., USA) were determined in duplicate by commercially available radioimmunoassay kits with an interassay coefficient of variation of less than $5 \%$ for insulin and $\mathrm{C}$ peptide and less than $8 \%$ for proinsulin. The intraassay coefficient of variation for the leptin RIA was $4.1 \%$, and the interassay coefficient of variation was $5.5 \%$. Measurement of IAPP (Peninsula, Belmont, Calif., USA) was as described previously [21]. Glycated haemoglobin $\left(\mathrm{HbA}_{1 \mathrm{c}}\right.$; upper limit of normal range $5.8 \%$ ) was quantified by on-line high pressure liquid chromatography (HPLC; C-R4A Chromatopac, Shimadzu, Kyoto, Japan) from capillary blood.

Body fat distribution was determined by measuring the waist-to-hip-ratio (WHR) in all women. In a subgroup of women with gestational diabetes $(n=12)$, and with clinical and metabolic characteristics similar to the whole group, body fat mass was determined by bioelectrical impedance analysis (BIA, Akern-RJL Systems) at post-partum re-evaluation.

Data analysis. Glucose, insulin and C peptide concentration data were analysed by a two compartment mathematical model [22] that reconstructs the patterns per unit volume of $C$ peptide secretion and posthepatic insulin appearance into peripheral circulation. This model [21, 22] has been implemented using PANSYM [23] and has already been used in normal and pathological conditions $[13,21,24,25]$. Briefly, the model estimates insulin secretion and degradation in the liver after oral glucose loading (the coefficient of variation $\mathrm{CV}$ of the estimates ranges around $5 \%)$. Calculations of glucose clearance were used as an index of insulin sensitivity $(\mathrm{CV}=7 \%)$ [26]. To estimate insulin sensitivity, data were derived from the plasma glucose concentrations at basal, 120 and $180 \mathrm{~min}$ and from insulin concentrations at zero and 120 min during the OGTT. Insulin sensitivity was computed by a model-derived formula
[26] which has been validated by the gold standard euglycaemic-hyperinsulinaemic clamp technique in healthy subjects, diabetic patients and obese subjects with glucose intolerance [27].

Statistical analysis. Results are expressed as means and standard error of the means (SEM) unless otherwise designated. Calculations were performed by the trapezoidal rule for AUC and by ANOVA with post-hoc tests by Tukey's adjustment for group differences. The paired Student's $t$-test was used for comparison within groups before and after delivery. Correlation coefficients were obtained by linear regression analysis. Furthermore, a stepwise multiple regression analysis was performed with leptin as the depending variable and with insulin, glucose, $\mathrm{C}$ peptide, proinsulin and BMI as the independent variables. A $p$-value of less than 0.05 was considered statistically significant.

\section{Results}

Plasma leptin was higher $(p<0.008)$ in women with gestational diabetes than in women with normal glucose tolerance and Type I diabetes and increased in all women when compared with women who were not pregnant $(8.2 \pm 1.3 ; p<0.0005$; Table 2$)$. Leptin concentrations were similar in pregnant women with normal glucose tolerance and in those with Type I diabetes matched for weight. No differences were seen between fasting and postprandial (OGTT) leptin concentrations in any group either during gestation (Table 2) or after delivery (Table 3 ). 
Table 2. Fasting (basal) and glucose-stimulated (30 minutes following ingestion of $75 \mathrm{~g}$ glucose loading) plasma hormone concentrations in pregnant women with gestational diabetes
(GDM), with normal glucose tolerance (NT) and with Type I Diabetes (DM I) at 28 weeks of gestation

\begin{tabular}{|c|c|c|c|c|}
\hline & & \multicolumn{3}{|c|}{ Pregnant Women } \\
\hline & & GDM & DM I & NT \\
\hline $\begin{array}{l}\text { Plasma concentrations } \\
\text { Leptin }(\mathrm{ng} / \mathrm{ml})\end{array}$ & $\begin{array}{l}\text { basal } \\
30 \mathrm{~min}\end{array}$ & $\begin{array}{l}24.9 \pm 1.6^{\mathrm{b}, \mathrm{a}} \\
25.4 \pm 2.0^{\mathrm{b}}\end{array}$ & $\begin{array}{l}19.0 \pm 2.1 \\
-\end{array}$ & $\begin{array}{l}18.2 \pm 1.5 \\
17.3 \pm 2.2\end{array}$ \\
\hline Insulin (pmol/l) & $\begin{array}{l}\text { basal } \\
30 \mathrm{~min}\end{array}$ & $\begin{array}{l}127.2 \pm 13.2^{b} \\
396.0 \pm 38.4\end{array}$ & $\begin{array}{l}134.4 \pm 16.3^{c} \\
-\end{array}$ & $\begin{array}{r}72.0 \pm 12.3 \\
531.2 \pm 63.1\end{array}$ \\
\hline Proinsulin (pmol/l) & $\begin{array}{l}\text { basal } \\
30 \mathrm{~min}\end{array}$ & $\begin{array}{l}21.7 \pm 2.8^{\mathrm{b}, \mathrm{a}} \\
36.1 \pm 3.0\end{array}$ & $-\quad 1.4 \pm 0.2^{\mathrm{c}}$ & $\begin{array}{l}11.7 \pm 2.0 \\
29.8 \pm 3.5\end{array}$ \\
\hline IAPP (pmol/l) & $\begin{array}{l}\text { basal } \\
30 \mathrm{~min}\end{array}$ & $\begin{array}{r}9.4 \pm 0.7 \\
13.9 \pm 0.7\end{array}$ & $\begin{array}{l}- \\
-\end{array}$ & $\begin{array}{r}7.1 \pm 1.5 \\
14.3 \pm 1.3\end{array}$ \\
\hline $\mathrm{TSH}(<4.0 \mathrm{mU} / \mathrm{l})$ & basal & $1.6 \pm 0.1$ & $1.6 \pm 0.4$ & $1.5 \pm 0.2$ \\
\hline
\end{tabular}

${ }^{\mathrm{a}} p<0.05$ GDM vs. DM I

b $p<0.05$ GDM vs NT

${ }^{c} p<0.05$ DM I vs NT

Table 3. Fasting (basal) and glucose-stimulated (30 min following $75 \mathrm{~g}$ oral glucose loading) plasma hormone concentrations 8 weeks after delivery in women with former gestational diabetes (GDM), with normal glucose tolerance (NT) during pregnancy and with Type I Diabetes (DM I) compared to healthy control women $(\mathrm{C})$ who were not pregnant

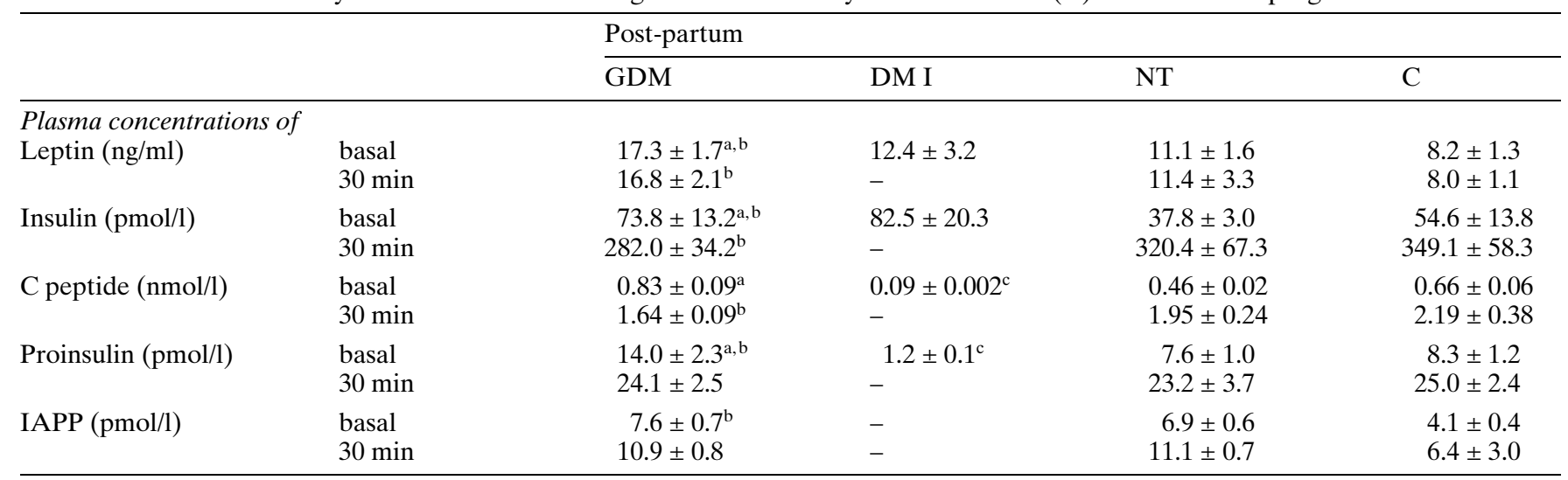

${ }^{\mathrm{a}} p<0.05$ GDM vs NT

${ }^{\mathrm{b}} p<0.05$ GDM vs C

${ }^{\mathrm{c}} p<0.05$ GDM vs DM I

In the women with gestational diabetes, fasting glucose $(p<0.005)$, insulin $(p<0.05)$, proinsulin $(p<0.01)$ and $\mathrm{C}$ peptide $(p<0.01)$ concentrations were higher than in the women with normal glucose tolerance as was $\mathrm{HbA}_{1 \mathrm{c}}(p<0.002)$ (Table 1). As expected, women with gestational diabetes had higher absolute plasma concentrations of insulin $(p<0.001)$, proinsulin $(p<0.0001)$ and $\mathrm{C}$ peptide $(p<0.0001)$ than women with Type I diabetes, who featured hyperglycaemia and almost complete insulin deficiency.

In the subgroup of patients where mathematical model analysis has been used, basal insulin secretion rate (BSR) and total insulin secretion (TIS) increased $(p<0.05)$ in the women with gestational diabetes (BSR: $48.5 \pm 6.3$, TIS: $36.7 \pm 3.5$ ) compared with the women with normal glucose tolerance (BSR: $31.3 \pm 2.8$, TIS: $26.4 \pm 2.6$ ). Accordingly, the OGTTderived insulin sensitivity was lower by $20 \%$ $(p<0.05)$ in women with gestational diabetes $\left(322.4 \pm 26.1 \mathrm{ml} \cdot \mathrm{min}^{-1} \cdot \mathrm{m}^{-2}\right)$ than in women with normal glucose tolerance $(401.3 \pm 15.2)$ and lower by $40 \%(p<0.002)$ than in women who were not pregnant $(515.3 \pm 30.0)$.

Pronounced insulin resistance was also reflected in a $40 \%$ lower mean basal glucose/insulin ratio in all 
A

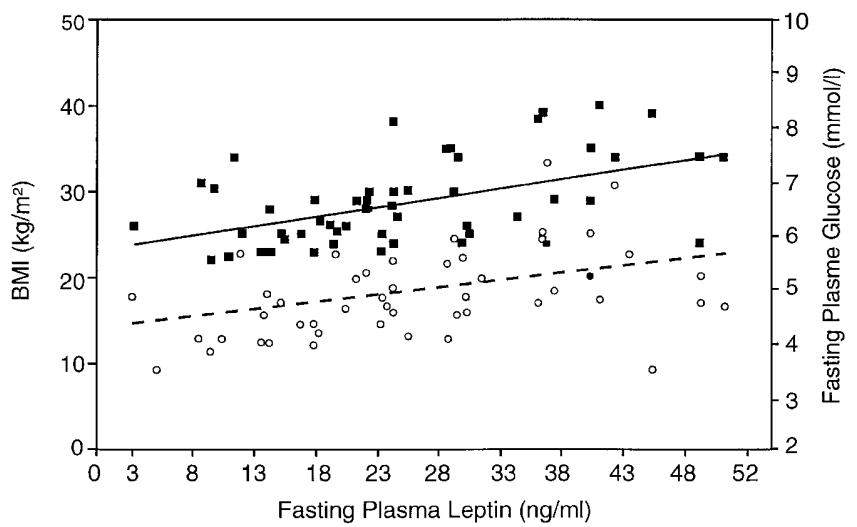

B

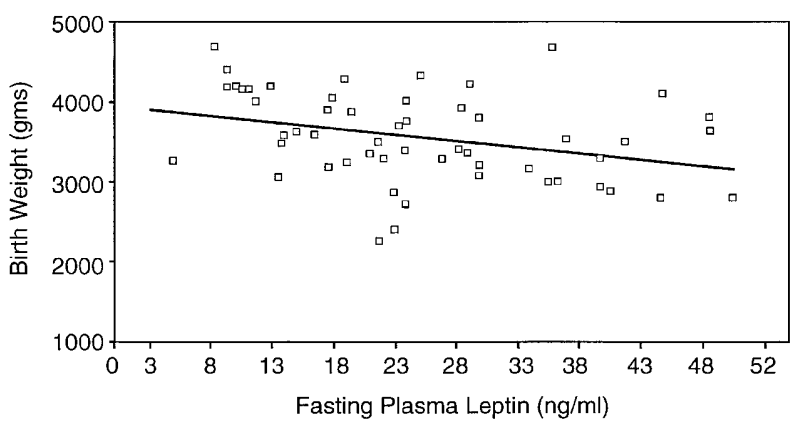

Fig. 1. Correlations between fasting plasma leptin concentration and (A) body mass index (BMI; $\square<0.0002, r=0.51$ ) as well as fasting plasma glucose concentration $(\bigcirc p<0.01$, $r=0.35)$ at gestational weeks 28 in patients with gestational diabetes, and (B) birth weight of their newborns $(\square \mathrm{p}<0.01$, $\mathrm{r}=-0.37)$

women with gestational diabetes compared with women with normal glucose tolerance (Table 1). Despite greatly increased plasma glucose concentrations $30 \mathrm{~min}$ after $75 \mathrm{~g}$ glucose ingestion (Table 1) the increment $\left(\delta^{0-30}\right)$ in beta-cell hormones' concentra- tions was even lower $(p<0.01)$ in women with gestational diabetes $\left(\delta^{0-30}: 268.8 \pm 30.3 \mathrm{pmol} / 1\right.$ for insulin and $1.24 \pm 0.10 \mathrm{nmol} / \mathrm{l}$ for $\mathrm{C}$ peptide) than in women with normal glucose tolerance $\left(\delta^{0-30}: 459.2 \pm 56.5\right.$ $\mathrm{pmol} / \mathrm{l}$ and $1.75 \pm 0.24 \mathrm{nmol} / \mathrm{l}$, respectively) showing a gestational diabetes specific defect in stimulated insulin secretion.

The pregnancy-induced increase at term in mean body weight $(\mathrm{kg})$ was about $15 \%$ and the mean birth weight (gms) of their newborn babies was $4 \%$ lower in women with gestational diabetes than in women with normal glucose tolerance (Table 4). Placental weight, the ponderal index and IGF-1 (somatomedin) were not different between women with gestational diabetes and women with normal glucose tolerance. Birth weight was similar between women with gestational diabetes on medical nutrition therapy only and those requiring insulin therapy. In Type I diabetes, however, the newborn children were about $15 \%$ heavier despite earlier delivery (Table 4).

Correlations. Correlations were seen between fasting plasma leptin and fasting plasma glucose $(p<0.01$, $r=0.35$; Fig. 1A), fasting plasma insulin $(p<0.004$, $r=0.38)$, proinsulin $(p<0.04, r=0.31)$, basal insulin secretion rate (BSR; $p<0.04, r=0.65)$ and total insulin secretion (TIS; $p<0.03, r=0.56$ ). Furthermore, a correlation was apparent between leptin and the systolic blood pressure $(p<0.02, r=0.35)$.

Fasting plasma leptin correlated in women with gestational diabetes with BMI before pregnancy $(p<0.007, r=0.46)$ and at gestational week 28 $(p<0.0002, r=51$; Fig. $1 \mathrm{~A})$, at term $(p<0.0005$, $r=0.55)$ and at 8 weeks after delivery $(p<0.0001$, $r=0.67)$ as well as with overall pregnancy induced maternal weight gain $(p<0.009, r=0.37)$. Inverse correlations were observed between fasting plasma leptin and fasting glucose/insulin ratio $(p<0.002$, $r=-0.45)$, placental weight $(p<0.03, r=-0.63)$ and the birth weight of the newborn babies $(p<0.01$, $r=-0.37$; Fig.1B). Noteworthy is that birth weight

Table 4. Obstetric data of the pregnant women with gestational diabetes (GDM), with normal glucose tolerance (NT) and with Type I Diabetes (DM I)

\begin{tabular}{|c|c|c|c|}
\hline & \multicolumn{3}{|c|}{ Pregnant Women } \\
\hline & GDM & DM I & NT \\
\hline Parity & $0.9 \pm 0.4$ & $1.4 \pm 0.5$ & $0.5 \pm 0.3$ \\
\hline BMI at term $\left(\mathrm{kg} / \mathrm{m}^{2}\right)$ & $30.1 \pm 0.9$ & $29.8 \pm 0.9$ & $30.2 \pm 0.8$ \\
\hline Total maternal weight gain $(\mathrm{kg})$ & $12.7 \pm 0.6$ & $16.3 \pm 2.1$ & $14.8 \pm 1.1$ \\
\hline Gestational weeks at delivery & $39.7 \pm 0.1 *$ & $38.5 \pm 0.4^{+}$ & $40.0 \pm 0.2$ \\
\hline Birth weight of the newborns $(\mathrm{g})$ & $3553.9 \pm 78.3^{*}$ & $4118.0 \pm 208.2^{+}$ & $3670.6 \pm 98.2$ \\
\hline PlacentalWeight $(\mathrm{g})$ & $649.5 \pm 22.3$ & $745.0 \pm 38.5$ & $656.7+33.1$ \\
\hline
\end{tabular}

$* p<0.05$ GDM vs DM I

${ }^{+} p<0.05$ DM I vs NT

$\S p<0.05$ GDM vs NT 
Table 5. Characteristics 8 weeks after delivery of women with former gestational diabetes (GDM), with normal glucose tolerance during pregnancy (NT) and with Type I Diabetes (DM I) as well as healthy control women who were not pregnant (C)

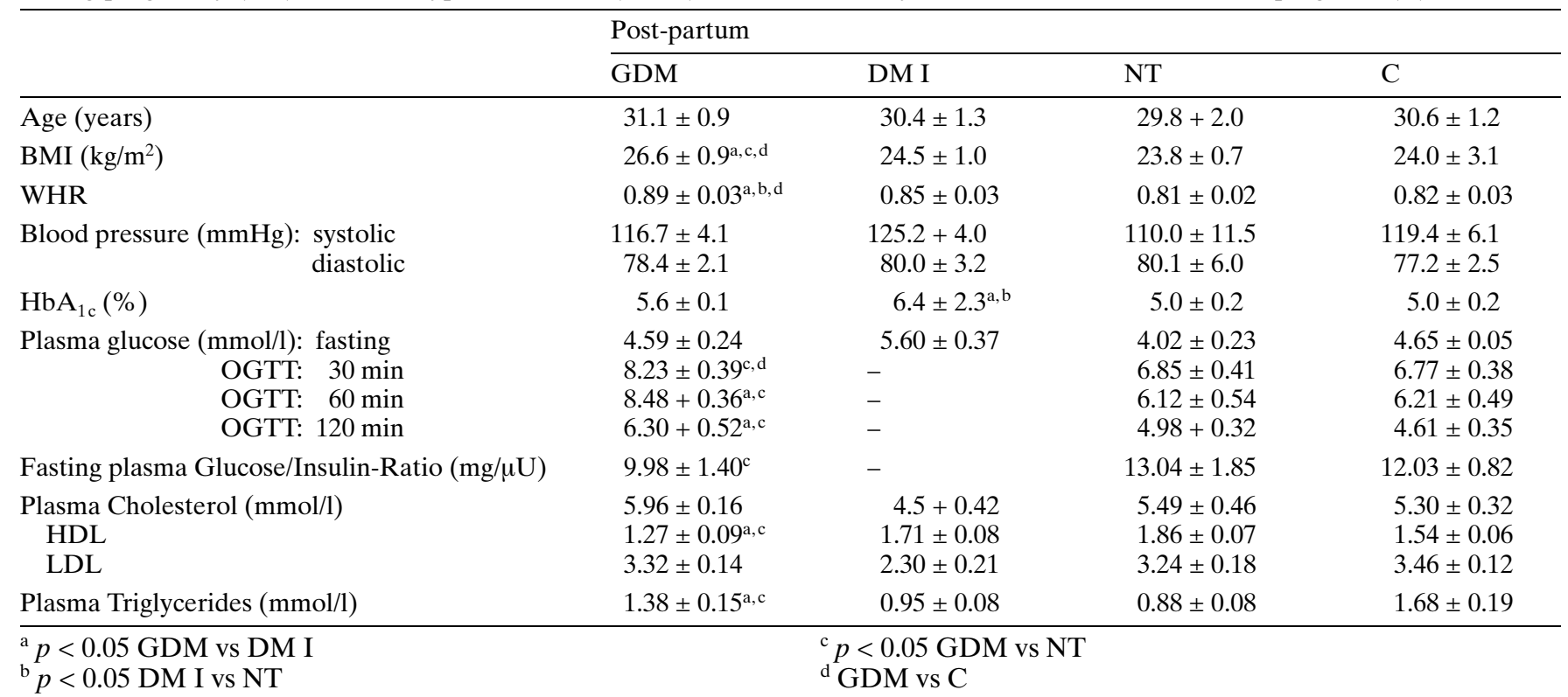

was not correlated with pregestational weight, maternal weight gain or $\mathrm{HbA}_{1 \mathrm{c}}$ in women with gestational diabetes, while birth weight only correlated with maternal weight gain in women with normal glucose tolerance $(p<0.03, r=0.40)$. In the total group of pregnant women with and without diabetes $(n=90)$ maternal leptin, however, also correlated inversely with birth weight $(p<0.0003, r=-0.39)$.

In subgroup analysis in women with gestational diabetes an inverse correlation was also apparent between plasma leptin and the insulin sensitivity index $(p<0.006, r=-0.61)$, which itself was related to the birth weight of the newborn babies $(p<0.05$, $r=0.45)$ and placental weight $(p<0.05, r=0.76)$.

Stepwise multiple regression analysis revealed that only glucose, $\mathrm{HbA}_{1 \mathrm{c}}$ and $\mathrm{BMI}$ had an independent influence on plasma leptin when all variables were taken into account.

After Delivery. Eight weeks after delivery glucose tolerance was normalized in women with gestational diabetes. Insulin sensitivity improved in women with gestational diabetes by $40 \%\left(452.1 \pm 25.3 \mathrm{ml} \cdot \mathrm{min}^{-1}\right.$ $\left.\cdot \mathrm{m}^{-2}, p<0.005\right)$, but remained different from women who were not pregnant and women with normal glucose tolerance by about $12 \% \quad(514.4 \pm 31.2)$ $(p<0.05)$. Plasma leptin decreased $(p<0.0005)$ in women with gestational diabetes by $32 \%$, but did not completely normalize ( $p<0.05$ vs C; Table 3 ). In women with normal glucose tolerance and Type I diabetes, however, plasma leptin did not differ from women who were not pregnant anymore.

After delivery the BMI rose $(p<0.03)$ in women with gestational diabetes compared to women with normal glucose tolerance and Type I diabetes. Women with gestational diabetes also featured a significantly increased WHR compared with all other groups, as well as the lowest plasma concentrations of HDL-cholesterol and higher plasma triglycerides than women with normal glucose tolerance and Type I diabetes (Table 5).

In parallel, leptin correlated with insulin $(p<0.05$; $r=0.32)$, proinsulin $(p<0.05, r=0.33)$, C peptide $(p<0.05, r=0.33)$ and glucose $(p<0.05, r=0.41)$ and inversely with the fasting glucose/insulin ratio (0.002, $r=-0.57)$. Accordingly, in subgroup analysis leptin was again closely related to the insulin sensitivity index $(p<0.03, r=-0.65)$.

In all women with gestational diabetes stepwise multiple regression analysis showed that only glucose and BMI had an independent influence on plasma leptin. Leptin correlated markedly post-partum with BMI $(p<0.001, r=0.61)$, WHR $(p<0.01 ; r=0.72)$ and body fat mass $(p<0.01, r=0.70 ; n=12)$.

No differences were seen in plasma concentrations of glucose, beta-cell hormones and leptin during the OGTT at gestational week 28 and post-partum, as well as in $\mathrm{HbA}_{1 \mathrm{c}}$ and anthropometric characteristics during pregnancy and after delivery, between the women on medical nutrition therapy and those with additional insulin treatment. Only insulin and C peptide concentrations at $30 \mathrm{~min}$. after glucose ingestion and their increase relative to the baseline were lower $(p<0.04)$ in women with gestational diabetes requiring insulin therapy during pregnancy. 


\section{Discussion}

Pregnancy and gestational diabetes provide a unique possibility to study the relation between plasma leptin and changes in body weight, insulin resistance and insulin secretion. In accordance with other studies [7-10, 28], plasma leptin increased in this study in all women who were pregnant when compared with healthy women of similar age and pregestational BMI who were not pregnant. That increase in plasma leptin in pregnancy goes hand-in-hand with increased free plasma concentrations and alterations in leptinbinding proteins $[10,29]$. The cause and functional role of increased leptin release during pregnancy is not clear, although the placenta has been considered a major source of leptin synthesis and secretion both into the maternal and the fetal circulation [8]. Gestational hormones, most of all oestrogens and cortisol also stimulate leptin production by adipose tissues [28]. The increase in body weight and the accumulation of body fat in the first two trimesters of pregnancy could therefore be main contributors to increased leptin release. It could, however, also be secondary to hyperinsulinaemia $[30,31]$, as insulin resistance and a compensatory increase in insulin secretion are physiological characteristics of late pregnancy.

Gestational diabetes is frequently found in women at high risk for obesity, diabetes and cardiovascular disease in later life, a cluster of diseases which is shown in this study to be aligned with increased plasma leptin concentrations both during pregnancy and post-partum. Decreased plasma leptin concentrations have only been found once in women with very mild abnormalities in glucose metabolism during pregnancy when compared with women who have normal pregnancy [32]. This observation conflicts with our longitudinal study, while the observation of similar plasma leptin concentrations in women with normal glucose tolerance and Type I diabetes are in accordance with others $[9,10]$.

Various cross-sectional studies have consistently found no differences in plasma leptin concentrations between subjects with and without diabetes with a similar body weight [4, 33-35] with one exception [36], where plasma leptin concentration in diabetes patients was higher. An association between increased plasma leptin concentrations and glucose intolerance has been reported in normal-weight women [37] and related to an increased risk for developing of Type II diabetes [38]. Thus, the potential interaction between insulin secretion, insulin sensitivity and leptin still remains a matter for debate [31, 39-42].

Many [43-46] but not all [47] previous cross-sectional studies in the general population and in subjects at risk for Type II diabetes have shown an inverse relation between plasma leptin concentrations and insulin sensitivity. Thus, leptin could either just reflect an increase in body fat mass or contribute to the regulation of insulin resistance/insulin secretion and thereby be involved in the pathophysiology of Type II diabetes. This contention is strenghtened by the direct inhibitory effect of plasma leptin on insulin secretion [48], suggesting hyperleptinaemia to be a missing link in the metabolic syndrome [33].

Although gestational diabetes shares many features of the insulin resistance syndrome [49], no change was observed in plasma leptin following oral glucose loading despite increased insulin secretion in this study as well as by others $[50,51]$. Noteworthy is the impaired stimulated insulin secretion for prevailing insulin sensitivity despite post-prandial hyperglycaemia compared to normal glucose tolerance. The fact that short-term changes in glucose-insulin homeostasis did not affect leptin secretion, although leptin is clearly associated with chronic hyperinsulinaemia at late second trimester of pregnancy, suggests that leptin is primarily a long-term adiposity signal rather than a short-term feeding-related satiety signal. In addition, fasting leptin also correlated with plasma glucose and inversely with the basal glucose/ insulin ratio, a commonly used surrogate parameter of insulin sensitivity. The observation that only glucose and BMI were independent predictors of plasma leptin indicates that the functional relation between leptin and insulin could just reflect a pre-existing metabolic syndrome. Indeed model analysis of OGTTs in subgroups confirmed pronounced insulin resistance in gestational diabetes to be strongly related to increased plasma leptin when compared with all other groups.

It is noteworthy that leptin also correlated with systolic blood pressure, triglycerides and the WHR after delivery, other important covariants of the metabolic syndrome. In this context it is of interest that leptin seems to promote fatty acid oxidation and a decrease in adipose mass [2, 52], which affects muscle insulin sensitivity and thereby regulates peripheral glucose metabolism.

The observed positive correlation between plasma leptin concentrations and the maternal BMI during pregnancy and gestational weight gain is in accordance with many $[9,32,53]$ but not all previous studies in pregnancy $[28,54]$. The $\mathrm{BMI}$ in pregnancy is an imprecise measure of the amount of body fat stores and relates to the fetal weight as well as to placenta size, amniotic fluid and maternal fluid expansion. Fat accumulation during pregnancy in women of developed countries correlates with, and explains around $70 \%$ of the variation in total gestational weight gain [55] as total body fat mass increases by $20-30 \%$ relative to the weight of women who are not pregnant to a maximum at around 30 weeks of gestation [56].

In women who are not pregnant plasma leptin closely relates to body fat mass and BMI. A similar correlation is also observed during pregnancy [57], where plasma leptin peaks in the late phase of the 
second trimester and relates to BMI post-partum. Interestingly, although BMI before and during pregnancy was similar between groups and overall maternal weight gain even lower in women with gestational diabetes, BMI post-partum remained significantly higher in women with gestational diabetes than in the women with normal glucose tolerance and Type I diabetes. It thus reflects the post-partal inability of women with gestational diabetes to normalize their body weight to the same extent as other women. This finding was attributed to a clear relation between plasma leptin and increased body fat content after delivery in women with gestational diabetes. In this context it is of note that higher plasma leptin concentrations at entry to prenatal care predicted weight gain as well as post-partum weight retention [58]. Similar findings have been observed outside pregnancy in a 5-year observational study in Japanese Americans, whose weight gain related to plasma leptin at baseline [59]. Overall it seems that pregnancy precipitates gestational diabetes in those with a pre-established latent metabolic syndrome similar to a cortisol glucose tolerance test [60].

Maternal leptin homeostasis does not seem to directly influence fetal plasma leptin concentrations, which in some $[53,54,61]$ but not all $[9,62]$ studies closely relates to birth weight and possibly also to maternal plasma leptin in the third trimester [53]. In our study birth weight was not related to maternal pregestational weight, overall weight gain and $\mathrm{HbA}_{1 \mathrm{c}}$ in women with gestational diabetes, but inversely with maternal plasma leptin and maternal insulin resistance at 28 gestational weeks. Although this observation suggests leptin is involved in the regulation of fetal growth in women with gestational diabetes, such a relation could be confounded by treatment effects.

In conclusion, higher plasma leptin concentrations are observed in noticeably insulin-resistant women with gestational diabetes both during pregnancy and post-partum when compared with hyperglycaemic women who were pregnant and who had Type I diabetes and healthy women, despite their similar pregestational weight. These findings indicate an association of leptin with parameters of glucose metabolism in gestational diabetes and make hyperleptinaemia a marker of a latent metabolic syndrome which in pregnancy is transiently but reversibly transformed in a gestational diabetes state.

Acknowledgements. This study was supported by a grant of the Austrian Science Foundation No. P14515-PAT.

\section{References}

1. Jeanrenaud FR, Jeanrenaud B (1996) Obesity, leptin and the brain. N Engl J Med 334: 324-325

2. Frühbeck G, Salvador J (2000) Relation between leptin and the regulation of glucose metabolism. Diabetologia 43: 3-12
3. LF Van Gaal, MA Wauters, IL Mertens, RV Considine, IH De Leeuw (1999) Clinical endocrinology of human leptin. Int J Obes 23 [Suppl 1]: 29-36

4. Haffner SM, Stern MP, Miettinen H, Wie M, Gingerich RL (1996) Leptin concentrations in diabetic and non-diabetic Mexican-Americans. Diabetes, 45: 822-824

5. Saad MF, Damani S, Gingerich RL et al. (1997) Sexual dimorphism in plasma leptin concentration. J Clin Endocrinol Metab 82: 579-684

6. Tritos NA, Mantzoros CS (1997) Leptin: its role in obesity and beyond. Diabetologia 40: 1371-1379

7. Tamura T, Goldenberg R, Johnston KE, Cliver SP (1998) Serum leptin concentrations during pregnancy and their relationship to foetal growth. Obstet Gynecol 91: 389-395

8. Senaris R, Garcia-Caballero T, Casabiell X (1997) Synthesis of leptin in human placenta. Endocrinology 138: 4501-4504

9. SM Stock, Bremme K (1998) Elevation of plasma leptin during pregnancy in normal and diabetic women. Metabolism 47: 840-843

10. K Lewandowski, CJ O'Callaghan, D Dunlop, GF Medley, P O'Hare, G Brabant (1999) Free leptin, bound leptin, and soluble leptin receptor in normal and diabetic pregnancies. J Clin Endocrinol Metab 84: 300-306

11. Kühl C (1991) Insulin secretion and insulin resistance in pregnancy and women with gestational diabetes. Diabetes 40 [Suppl 2]: $18-24$

12. Ryan EA, O'Sullivan MJ, Skyler JS (1985) Insulin action during pregnancy. Studies with the euglycemic clamp technique. Diabetes 34: 380-389

13. Kautzky-Willer A, Prager R, Waldhäusl W et al. (1997) Pronounced insulin resistance and inadequate B-cell secretion in lean gestational diabetes mellitus during and after pregnancy. Diabetes Care 20: 1717-1723

14. Oats JN, Beischer NA, Grant PT (1988) The emergence of diabetes and impaired glucose tolerance in women who had gestational diabetes In: Weiss PA, Coustan DR (eds) Gestational Diabetes. Springer Verlag, New York, pp 199-207

15. Pendergrass M, Fazioni E, De Fronzo R (1996) Non-insulindependent diabetes mellitus and gestational diabetes mellitus: same disease, another name? Diabetes Rev 3: 566-583

16. Pettitt DJ, Nelson RG, Saad MF, Bennett PH, Knowler WC (1993) Diabetes and obesity in the offspring of Pima Indian women with diabetes during pregnancy. Diabetes Care 16 [Suppl 1]: 310-314

17. Silverman BL, Rizzo TA, Cho NH, Metzger BE (1998) Longterm effects of the intrauterine environment. Diabetes Care 21 [Suppl 2]: 142-149

18. Law CM, Gordon GS, Shiell AW, Barker DJP, Hales CN (1995) Thinness at birth and glucose tolerance in seven year old children. Diabet Med 12: 24-29

19. Barker DJP, Hales CN, Fall CHD, Osmond C, Philipps K, Clark PMS (1993) Type II (non-insulin-dependent) diabetes mellitus, hypertension and hyperlipidemia (syndrome X): relation to reduced foetal growth. Diabetologia 36: 62-67

20. Hattersley AT, Tooke JE (1999) The foetal insulin hypothesis: an alternative explanation of the association of low birth weight with diabetes and vascular disease. Lancet 353: 1789-1792

21. Kautzky-Willer A, Thomaseth K, Pacini G et al. (1994) Role of islet amyloid polypeptide secretion in insulin-resistant humans. Diabetologia 37: 188-194

22. Thomaseth K, Kautzky-Willer A, Ludvik B, Prager R, Pacini G (1996) Integrated mathematical model to assess B-cell activity during the oral glucose tolerance test. Am J Physiol 270: E522-E531

23. Thomaseth K (1994) PANSYM : a symbolic equation generator for mathematical modeling, analysis and control of metabolic and pharmacokinetic systems. Comput Methods Prgrams Biomed 42: 99-112

24. Kautzky-Willer A, Thomseth K, Clodi M et al. (1996) B-cell activity and hepatic insulin extraction following dexametha- 
sone administration in healthy subjects. Metabolism 45: 486-491

25. Kautzky-Willer A, Thomaseth K, Ludvik B et al. (1997) Elevated islet amyloid pancreatic polypeptide and proinsulin in lean gestational diabetes. Diabetes 46: 607-614

26. Pacini G, Nolan JJ, Mari A (1999) A model derived measure of insulin sensitivity from the oral glucose test. Med Biol Eng Comput 37 [Suppl 2]: 1170-1171

27. Mari A, Pacini G, Nolan JJ (1999) A new method for assessing insulin sensitivity from oral glucose tolerance test. Diabetes 48: A286 (Abstract)

28. Sivan E, Whittaker PG, Sinha D et al. (1998) Leptin in human pregnancy: The relationship with gestational hormones. Am J Obstet Gynecol 179: 1128-1132

29. Liu C, Liu X, Barry G, Ling N, Maki R, De Souza E (1997) Expression and characterization of a putative high affinity human soluble leptin receptor. Endocrinology 138: 3548-3554

30. Leroy P, Dessolin S, Vilageois P et al. (1996) Expression of ob gene in adipose cells-regulation by insulin. J Biol Chem 271: 2365-2368

31. Kamohara S, Burcelin R, Hajaas J, Friedman JM, Charron MJ (1997) Acute stimulation of glucose metabolism in mice by leptin treatment. Nature 389: 374-377

32. Festa A, Shnawa N, Krugluger W, Hopmeier P, Schernthaner G, Haffner S (1999) Relative hypoleptinemia in women with mild gestational diabetes mellitus. Diabet Med 16: 656-662

33. De Courten M, Zimmet P, Hodge A et al. (1997) Hyperleptinemia the missing link in the metabolic syndrome? Diabet Med 14: 200-208

34. Malmström R, Taskinen MR, Karonen SL, Yki-Jarvinen H (1996) Insulin increases plasma leptin concentrations in normal subjects and patients with NIDDM. Diabetologia 39: 993-996

35. Mc Gregor GP, Desaga JF, Ehlenz K et al. (1996) Radioimmunological measurement of leptin in plasma of obese and diabetic human subjects. Endocrinology 137: 1501-1504

36. Widjaja A, Stratton J, Horn R, Holman R, Turner R, Brabant G (1997) UKPDS; plasma leptin, obesity and plasma insulin in type 2 diabetic subjects. J Clin Endocrinol Metab 82: 654-657

37. Haanley AJ, Harris SB, Gao Xj, Kwan J, Zinman B (1997) Serum immunoreactive leptin concentrations in a Canadian aboriginal population with high rates of NIDDM. Diabetes Care 20: 1408-1415

38. MJ McNeely, Boyko EJ, Weigle DS et al. (1999) Association between baseline plasma leptin levels and subsequent development of diabetes in Japanese Americans. Diabetes Care 22: 65-70

39. Seufert J, Kiefer TJ, Leech CA et al. (1999) Leptin suppression of insulin secretion and gene expression in human pancreatic islets; Implifications for the development of adipogenic diabetes mellitus. J Clin Endocrinol Metab 84: 670-676

40. Turpeinen AK, Haffner SM, Louheranta AM et al. (1997) Serum leptin in subjects with impaired glucose tolerance in relation to insulin sensitivity and first phase insulin response. Int $\mathrm{J}$ Obes 21: 284-287

41. Muller G, Ertl J, Gerl M, Preibisch G (1997) Leptin impairs metabolic actions of insulin in isolated rat adipocytes. J Biol Chem 272: 10585-10593

42. Rossetti L, Massillon D, Barzilai N et al. (1997) Short term effects of leptin on hepatic gluconeogenesis and in vivo insulin action. J Biol Chem 272: 27758-27763

43. Dua A, Hennes MI, Hoffmann RG et al. (1996) Leptin: a significant indicator of total body fat but not of visceral fat and insulin sensitivity in African-american women. Diabetes 45: 1635-1637

44. Nyholm B, Fisker S, Lund S, Moller N, Schmitz O (1997) Increased circulating leptin concentrations in insulin-resistant first degrees relatives of patients with non-insulin-dependent diabetes mellitus: relationship to body composition and insulin sensitivity but not family history of non-insulin dependent diabetes mellitus Eur J Endocrinol 136: 173-179

45. Donahue RP, Prineas RJ, Danahue R et al. (1999) Is fasting leptin associated with insulin resistance among nondiabetic individuals ? Diabetes Care 22: 1092-1096

46. Echwald SM, Clausen JO, Hansen T et al. (1999) Analysis of the relationship between fasting serum leptin levels and estimates of beta-cell function and insulin sensitivity in a population sample of 380 healthy young caucasians. Eur J Endocrinol 140: $180-185$

47. Kennedy A, Gettys TW, Watson P et al. (1997) The metabolic significance of leptin in humans. Gender-based differences in relationship to adiposity, insulin sensitivity, and energy expenditure. J Clin Endocrinol Metab 82: 1293-1300

48. Emilsson V, Liu YL, Morton NM, Davenport M (1997) Expression of the functional leptin receptor mRNA in pancreatic islets and direct inhibitory action of leptin on insulin secretion. Diabetes 46: 313-316

49. Clark CHM, Qiu CH, Amerman B et al. (1997) Gestational diabetes: should it be added to the syndrome of insulin resistance? Diabetes Care 20: 867-871

50. Sinha MK, Ohannesian JP, Heiman ML et al. (1996) Nocturnal rise of leptin in lean, obese and non-insulin dependent diabetes mellitus subjects. J Clin Invest 97: 1344-7

51. Kautzky-Willer A, Ludwig C, Nowotny P et al. (1999) Elevation of plasma leptin concentrations in obese hyperinsulinemic hypothyroidism before and after treatment. Eur J Clin Invest 29: 395-403

52. Levin N, Nelson C, Gurney A, Vandlen R, de Sauvage F (1996) Decreased food intake does not completely account for adiposity reduction after ob protein infusion. Proc Natl Acad Sci USA 93: 1726-1730

53. Shaarawy K, El-Mallah SY (1999) Leptin and gestational weight gain. Relation of maternal and cord blood leptin to birth weight. J Soc Gynecol Investing 6: 70-73

54. Schubring C, Kiess W, Englaro P et al. (1997) Levels of leptin in maternal serum, amniotic fluid and arterial and venous cord blood, relation to neonatal and placental weight. J Clin Endocrinol Metab 82: 1480-1483

55. King JC, Butte NF, Bronstein MN, Kopp LE, Lindquist SA (1994) Energy metabolism during pregnancy: influence of maternal energy status. Am J Clin Nutr 59: 439-458

56. Goldberg GR, Prentice AM, Coward WA et al. (1993) Longitudinal assessment of energy expenditure of the dizbly labelled water method. Am J Clin Nutr 57: 494-505

57. Sattar N, Greer IA, Pirwani I, Gibson J, Wallace AM (1998) Leptin levels in pregnancy: marker for fat accumulation and mobilisation? Acta Obstet Gynecol Scand 77: 278-283

58. Stock P, Scholl Th, Schluter M, Schroeder CH (1998) Plasma leptin influences gestational weight gain and postpartum weight retention. Am J Clin Nutr 68: 1236-1240

59. Chessler SD, Fujimoto WY, Shofer JB, Boyko EJ, Weigle DS (1998) Increased plasma leptin levels are associated with fat accumulation in Japanese-Americans. Diabetes 47: 239-242

60. Henriksen JE, Alford F, Ward GM, Beck-Nielsen H (1997) Risk and mechanism of dexamethasone-induced deterioration of glucose tolerance in non-diabetic first degree relatives of NIDDM patients. Diabetologia 40: 1439-1448

61. Gross GA, Solenberger T, Philpott T, Holcomb WL, Landt M (1998) Plasma leptin concentrations in newborns of diabetic and non-diabetic mothers. Am J Perinatol 15: 243-247

62. Persson B, Westgren M, Celsi G, Nord E, Örtqvist E (1999) Leptin concentrations in cord blood in normal newborn infants and offspring of diabetic mothers. Horm Metab Res 31: 467-471 